Article

\title{
Migrant Students' Sense of Belonging and the Covid-19 Pandemic: Implications for Educational Inclusion
}

\author{
Nikolett Szelei ${ }^{1, *}$, Ines Devlieger ${ }^{1}$, An Verelst ${ }^{1}$, Caroline Spaas ${ }^{2}$, Signe Smith Jervelund ${ }^{3}$, \\ Nina Langer Primdahl ${ }^{3}$, Morten Skovdal ${ }^{3}$, Marianne Opaas ${ }^{4}$, Natalie Durbeej ${ }^{5}$, Fatumo Osman ${ }^{5,6}$, \\ Emma Soye $^{7}$, Hilde Colpin ${ }^{8}$, Lucia De Haene ${ }^{2}$, Sanni Aalto ${ }^{9}$, Reeta Kankaanpää ${ }^{9}$, Kirsi Peltonen ${ }^{9,10,11}$, \\ Arnfinn J. Andersen ${ }^{4}$, Per Kristian Hilden ${ }^{4}$, Charles Watters ${ }^{7}$, and Ilse Derluyn ${ }^{1}$ \\ ${ }^{1}$ Department of Social Work and Social Pedagogy, Ghent University, Belgium \\ 2 Parenting and Special Education Research Unit, KU Leuven, Belgium \\ ${ }^{3}$ Department of Public Health, University of Copenhagen, Denmark \\ ${ }^{4}$ Norwegian Centre for Violence and Traumatic Stress Studies, Norway \\ ${ }^{5}$ Department of Public Health and Caring Sciences, Uppsala University, Sweden \\ ${ }^{6}$ School of Health and Welfare, Dalarna University, Sweden \\ 7 School of Education and Social Work, University of Sussex, UK \\ ${ }^{8}$ School Psychology and Development in Context Research Unit, KU Leuven, Belgium \\ ${ }^{9}$ Faculty of Social Sciences, Tampere University, Finland \\ 10 Department of Child Psychiatry, University of Turku, Finland \\ 11 INVEST Research Flagship Center, University of Turku, Finland \\ * Corresponding author (nikolett.szelei@ugent.be)
}

Submitted: 15 November 2021 | Accepted: 10 January 2022 | Published: 19 May 2022

\begin{abstract}
This article investigates school belonging among migrant students and how this changed during the Covid-19 pandemic. Drawing on quantitative data gathered from 751 migrant students in secondary schools in six European countries (Belgium, Denmark, Finland, Norway, Sweden, and the UK), we examined the impact of Covid-19 school closures, social support, and post-traumatic stress symptoms on changes in school belonging. Linear regression showed a non-significant decrease in school belonging, and none of the studied variables had a significant effect on this change in our whole sample. However, sensitivity analysis on a subsample from three countries (Denmark, Finland, and the UK) showed a small but significant negative effect of increasing post-traumatic stress symptoms on school belonging during Covid-19 school closures. Given that scholarship on school belonging during Covid-19 is emergent, this study delineates some key areas for future research on the relationship between wellbeing, school belonging, and inclusion.
\end{abstract}

\section{Keywords}

Covid-19; inclusion; migrants; post-traumatic stress; school belonging; social support

\section{Issue}

This article is part of the issue "Educational Inclusion of Vulnerable Children and Young People after Covid-19" edited by Spyros Themelis (University of East Anglia) and Angela Tuck (Pakefield High School).

(C) 2022 by the author(s); licensee Cogitatio (Lisbon, Portugal). This article is licensed under a Creative Commons Attribution 4.0 International License (CC BY).

\section{Introduction}

The inclusion of migrant students is challenging for many educational systems. We use the term migrant as an "umbrella term" referring to "a person who moves away from his or her place of usual residence...temporarily or permanently, and for a variety of reasons" (International Organization for Migration [IOM], 2019, p. 132). While several considerable differences exist between migrants, here we focus on transnational migrants who migrated 
during childhood. Inclusion is understood as an overarching principle and a process whereby all students are provided with equal opportunities to participation and educational achievement (Ainscow et al., 2006; Booth \& Ainscow, 2002; UNESCO, 2005). In schools, a crucial component of fostering inclusion is building a community to which students feel they belong (Booth \& Ainscow, 2002; Kovač \& Vaala, 2021; Shaw et al., 2021). However, several issues still exist that may jeopardise migrant students' inclusion and school belonging (e.g., Abu El-Haj \& Skilton, 2017; Souto-Manning, 2021; Van Caudenberg et al., 2020). Such challenges are, among others, placing migrant students in separated newcomer or language classes that might lead many students to lower educational pathways and limited learning opportunities (Emery et al., 2021), schools' monolingual policies and teaching norms (Gogolin, 2021), school practitioners' challenges in teaching migrant and refugee children (Pastoor, 2015; Szelei et al., 2020), racialising and "othering" discourses (Ambrose, 2020; Souto-Manning, 2021; Szelei et al., 2021), and experiences of exclusion and victimisation in schools ( $D^{\prime}$ hondt et al., 2015; Adams-Wiggins, 2020). When taking these issues together, schools often create what Abu El-Haj and Skilton (2017) call an "illusion of inclusion."

These challenges of inclusion and belonging for migrant students existed long before Covid-19. However, with the closure of schools from March 2020 onwards, concerns about migrant students' access to education have gained renewed attention (European Commission Joint Research Centre [EC JRC], 2020; OECD, 2021). Teachers expressed anxieties about how to continue teaching and caring for migrant students, as school life, relationship building, and structural support were interrupted (Primdahl et al., 2021). There has also been a focus on the so-called "learning loss" (OECD, 2021) and "increased inequities" (EC JRC, 2020), often linked to the disadvantages of online teaching and distance learning for migrants. According to an OECD (2021) survey, only $44 \%$ of the surveyed countries implemented specific measures to ensure the online participation of migrant youth in schools during the first lockdown. This is alarming since students' smooth transition to online teaching might then overly depend on conditions at home, such as parents' familiarity with technology (Dimopoulos et al., 2021).

Another often-voiced concern related to Covid-19 has been the potentially deteriorating mental health of students. Some studies have described increases in depression and anxiety for adolescents during Covid-19 (Nearchou et al., 2020), yet other studies have not detected the pandemic's clear negative impact on mental health (Ramirez et al., 2021; Schwartz et al., 2021).

Furthermore, it has been noted that interrupted schooling was not necessarily a new phenomenon for many migrant students (Chang-Bacon, 2021). Before Covid-19, Potochnick (2018) found that migrant students with interrupted schooling did not differ in school engagement from their native-born peers even though their educational achievement was lower. Taking into account the concerns about the negative effects of the pandemic on students' wellbeing and education, and the specific issues affecting the educational inclusion of young migrants, there is still a need to investigate the impact of Covid-19 specifically on migrant students. While previous studies have investigated issues of school access, online learning, and mental health related to Covid-19, to our knowledge there is currently no study that examines the impact of Covid-19 on migrant students' sense of school belonging.

This article is part of a large project (RefugeesWell School) that implemented and assessed five schoolbased and social support-focused interventions to promote migrant students' wellbeing. The study took place in six European countries (Belgium, Denmark, Finland, Norway, Sweden, and the UK) and had a longitudinal design. The project was ongoing when Covid-19 was declared a pandemic, and this meant that many of the students who participated in the second assessment did so during home confinement. The impact of Covid-19 on assessment varied across the participating countries. In Sweden, all assessments at the second timepoint (T2) were completed before school closures, whereas in Belgium and Norway, all T2 assessments were conducted after schools closed. In Denmark, Finland, and the UK, T2 evaluations were collected both before and after Covid-19 school closures had commenced. Therefore, to map potential general tendencies among the groups that were and were not affected by Covid-19, we first present results with altogether 751 migrant students in all participating countries. Secondly, we conduct sensitivity analysis with 320 students in Denmark, Finland, and the UK, as these were the countries where T2 data were collected both before and after Covid-19 school closures were implemented.

The schools in this study followed the national measures of their respective countries to contain the spread of Covid-19, and closed fully (Belgium, Denmark, UK, and Norway) or partially (Finland) in March 2020. In Sweden, the participating schools remained open and they made autonomous decisions about the specific measures they would implement against Covid-19. In the other countries, distance learning and online teaching were implemented as much as possible. Already existing and newly developed digital platforms were used to sustain curricular learning. In Finland, while school closures applied to the general school population and extracurricular activities were cancelled for all students, migrant students were still allowed to attend face-to-face teaching. Schools in Norway were also permitted to follow this approach if they wished. In our study, some Norwegian schools returned to in-school teaching for migrant students before the general school closure ended but not immediately after the lockdown began.

Field observations in our project show that Covid-19 was a difficult experience for schools and migrant 
students. A lack of digital devices was observed in all the countries. Accessing online content was also difficult for many students due to a language barrier and a lack of close teacher support. In some cases, crowded home environments, lack of curricular learning support, and students' increased participation in family responsibilities (e.g., looking after younger siblings while parents worked) made remote learning challenging. At the same time, some teachers made remarkable efforts to remain in contact with their students and to support their learning and wellbeing. For example, some teachers regularly called students via phone, communicated through mobile phone applications, dropped off homework at students' homes or organised physical home visits. In sum, Covid-19 has brought on a new reality for most schools as they have had to create and utilise alternative ways of teaching and caring for migrant students. These changing conditions provided an opportunity to investigate the impact of Covid-19 school closures on school belonging among migrant students.

\section{Theoretical Underpinnings of School Belonging and Literature Review}

School belonging is an active and relational social process whereby students interact and connect with members of the school community and the broad school context (Halse, 2018; Kovač \& Vaala, 2021; Pincton \& Banfield, 2019; Puroila et al., 2021). School belonging is a multi-layered concept (Allen \& Kern, 2017; Allen et al., 2018; Halse, 2018; Puroila et al., 2021; Yuval-Davis, 2004), influenced by several demographic (e.g., gender, age, ethnicity, school location), individual (e.g., personal characteristics, mental health), social (e.g., support from teachers, parents, peers), and environmental (e.g., school climate) factors (Allen \& Kern, 2017, p. 25). We follow Allen et al. (2018) who apply Bronfenbrenner's (1994) bioecological model to the concept of school belonging. In this view, school belonging is a result of interactions between the individual student and the broader complex environment, such as peers and teachers in schools, families, school culture, school policies, norms, and values (Allen et al., 2018, p. 4). More specifically, we investigate the effect of some demographic (gender, age), individual (mental health), social (social support from friends and family), and environmental (Covid-19 school closures, daily stressors) factors on the potentially changing feeling of belonging.

School belonging has been established in the literature as a positive predictor of educational achievement, academic self-efficacy and attitudes (Fong Lam et al., 2015; Niehaus et al., 2012), and wellbeing (Kia-Keating \& Ellis, 2007; Nuttman-Shwartz, 2019; Scharpf et al., 2020). Previous research has shown that positive peer relationships, connectedness with friends (Allen et al., 2018; Ambrose, 2020; Delgado et al., 2016; DeNicolo et al., 2017; Van Caudenberg et al., 2020), and parental support at home (Allen et al., 2018; Hu \& Wu, 2020) are linked to increased feelings of school belonging. Research has also found that school belonging forms a protective factor against the development of mental health problems (Kia-Keating \& Ellis, 2007; Nuttman-Shwartz, 2019; Scharpf et al., 2020). Fewer studies have investigated the role of mental health in the development of a sense of school belonging, but mental health problems are assumed to have a negative influence on school belonging (Allen \& Kern, 2017; Allen et al., 2018). This might be particularly relevant for migrant youth who often present with high levels of post-traumatic stress symptoms (Spaas et al., 2021).

School belonging is often a complex experience for migrant students whereby personal emotions and formal representations and norms of belonging interact with and conflict with each other (e.g., Ambrose, 2020; Gao et al., 2019; Puroila et al., 2021; Souto-Manning, 2021; Van Caudenberg et al., 2020; Yuval-Davis, 2004). DeNicolo et al. (2017) identify the quality of teacher-student and peer relationships, as well as migrant students' agency, as key components in creating a positive sense of belonging for migrant students. Friendships and social support from peers and family can foster belonging and wellbeing (Allen et al., 2018; Ho et al., 2017; Hu \& Wu, 2020; Nuttman-Shwartz, 2019). Schools can enhance feelings of belonging by facilitating newcomers' settlement in a new country, and by building positive social relationships in schools (Schweitzer et al., 2021). Using online spaces where migrant students can connect with peers and family members may help to alleviate exclusionary tendencies in schools (Rowan et al., 2021). Teachers' pedagogical practices (Edgeworth \& Santoro, 2015; Pendergast et al., 2018) also play a role in defining belongingness. Therefore, Edgeworth and Santoro (2015, p. 423) recommend developing "pedagogies of belonging" understood as "pedagogies that create all students in states of belonging."

Secondly, how migrants actively construct and forge new places and definitions for belonging highlight their resilience and agency (Gao et al., 2019; Moberg Stephenson \& Källström, 2020; Van Caudenberg et al., 2020). For example, children can adopt multiple identifications and points of belonging (Devine, 2009; Rutland et al., 2012), contradicting narrow definitions that usually surround them in society and education (e.g., "migrant" or "language learner"; Gao et al., 2019). For instance, in Gao et al. (2019), young people redefined belonging by drawing on notions such as multilingualism, personal emotions, and connectedness to the city where they lived. In Van Caudenberg et al. (2020), young migrant students actively resisted schools where they felt alienated and decided to attend other schools where they felt more belonging.

Furthermore, it is important to note that academic belonging (e.g., academic motivation, self-efficacy, performance) is also part of school belonging (Allen et al., 2018; Fong Lam et al., 2015; Pendergast et al., 2018). 
This is relevant for migrant students who often have high academic ambitions at the beginning of their schooling in a new country (Devine, 2009; Lynnebakke \& Pastoor, 2020; Van Caudenberg et al., 2020). For migrant students, schools may represent hopes and opportunities for social connections, learning ambitions, safety, and educational and societal progress in a new country (De Jacolyn et al., 2021; Devine, 2009; Lynnebakke \& Pastoor, 2020; Van Caudenberg et al., 2020). In sum, belonging is a complex issue for migrant students and can be developed in multiple ways, especially in contemporary societies where digital forms of communication are prevalent (Halse, 2018).

\section{Methodology}

\subsection{Data Collection and Participants}

Data collection took place within the RefugeesWellSchool study. This project implemented and evaluated five school-based interventions that focused on social support and social cohesion to promote migrant adolescents' wellbeing. The study applied a cluster randomised controlled trial design; school classes were therefore randomly assigned to participate in an intervention or a control group. The project collected quantitative data before (T1) and after (T2) the interventions were implemented. As the project was ongoing when Covid-19 was announced as a pandemic, some of the T2 data was collected during Covid-19 school closures.

Schools in the six countries were recruited based on the criteria of having a high proportion of new- comer migrant students in their school population or having newcomer/language classes for migrant students. Students, parents, and school practitioners were provided with an information sheet about the project. Information sessions were also organised where the researchers presented the project to the school community, using visual aids, PowerPoint presentations, and interpreters where possible. Consent was obtained from all students via informed consent forms, as well as via parental consent for those under the legal age of consent.

Quantitative longitudinal data was collected in 2019 and 2020 via a questionnaire that was available in 22 languages. We analyse data in two steps. First, we include responses from 751 students who replied at both $\mathrm{T} 1$ and T2 in all six countries (see the sociodemographic characteristics of this sample in Table 1). This step is necessary to detect whether general tendencies exist between the groups that were and were not affected by Covid-19 at T2. In this sample, time between the two measurement points ranged from 3-6 months. The age of participants ranged from $11-18$, with an average of 14.82 $(S D=1.57)$. Time spent in the host country ranged from 0 to 16 years, on an average of 3.31 years $(S D=3.44)$. 366 students completed T2 assessment before school closures and 385 did so after school closures. However, as noted previously, this distribution was unequal across the countries. Consequently, we conduct a sensitivity analysis with 320 students in Denmark, Finland, and the UK, as these were the countries where T2 data were collected both before and after Covid-19 school closures were implemented.

Table 1. Sociodemographic characteristics per T2 assessment Covid-19 group ( $N=751)$.

\begin{tabular}{|c|c|c|c|}
\hline $\begin{array}{l}\text { Sociodemographic } \\
\text { characteristic }\end{array}$ & $\begin{array}{l}\text { T2 assessment took place } \\
\text { before Covid-19 school } \\
\text { closures }(N=366)\end{array}$ & $\begin{array}{l}\text { T2 assessment took place } \\
\text { after Covid-19 school } \\
\text { closures started ( } \mathrm{N}=385)\end{array}$ & $\begin{array}{c}\text { Total } \\
(\mathrm{N}=751)\end{array}$ \\
\hline \multicolumn{4}{|l|}{ Gender } \\
\hline Females & 144 & 177 & 321 \\
\hline Males & 215 & 198 & 413 \\
\hline Other & 3 & 0 & 3 \\
\hline Unknown & 4 & 10 & 14 \\
\hline Age & 14.58 (SD 1.48) & 15.05 (SD 1.62) & $14.82(S D 1.57)$ \\
\hline Time spent in host country & 4.65 (SD 3.69) & 1.45 (SD 1.87) & 3.31 (SD 3.44) \\
\hline \multicolumn{4}{|l|}{ Country } \\
\hline Belgium & 0 & 182 & 182 \\
\hline Denmark & 80 & 63 & 143 \\
\hline Finland & 100 & 10 & 110 \\
\hline Norway & 0 & 125 & 125 \\
\hline Sweden & 124 & 0 & 124 \\
\hline UK & 62 & 5 & 67 \\
\hline \multicolumn{4}{|l|}{ Intervention group } \\
\hline Intervention & 227 & 235 & 462 \\
\hline Control & 139 & 150 & 289 \\
\hline
\end{tabular}




\subsection{Measures}

Students' sense of school belonging was measured by the Psychosocial Sense of School Membership (PSSM) scale, developed by Goodenow (1993) and validated in Cowden et al. (2018), Gaete et al. (2016), Goodenow (1993), and Kia-Keating and Ellis (2007). The PSSM items pose questions about students' perceptions of being accepted and involved in school, and how other students and teachers treat them. In this study, a shortened version of the original PSSM was used. Students were asked to rate nine items on a 5-point Likert scale ( $1=$ not at all true to 5 = completely true). Although this version was not validated in this study, we found it to be an appropriate measure based on the instrument's previous validity in several contexts.

Students' post-traumatic stress symptoms were measured by the Children's Revised Impact of Events Scale-8, developed by Perrin et al. (2005) and validated in Perrin et al. (2005) and Magalhães et al. (2018). This scale is often used with children aged between 8-18 to screen for post-traumatic stress disorder. Students rated eight items on a 4-point Likert scale ( $0=$ not all, $1=$ rarely, 3 = sometimes, $5=$ often).

Social support was measured by the Multidimensional Scale of Perceived Social Support (MSPSS) scale, developed by Zimet et al. (1988) and validated in Chou (2000) and Zimet et al. (1988). In this study, two subscales were used: $4+4$ items related to perceived support from family and friends, respectively. Both subscales followed a 4-point Likert scale (ranging from 1 = not at all to $4=a$ lot) and asked how much support students felt they received from family members and friends.

Daily stressors were examined using the Daily Stressors Scale for Young Refugees. The scale was developed by Vervliet et al. (2010) and previously applied in Vervliet et al. (2014). The original scale consists of 15 items measuring different types of daily stressors (e.g., social, material, discrimination, etc.). This scale has not yet been validated, but due to its relevance to the circumstances of migrant and refugee adolescents, we found it to be applicable to our study. In this project, we used six items of the original scale that measured students' perceived material safety on a 4-point Likert scale (1 = never to $4=$ always).

We also collected a wide range of sociodemographic information, including gender (male, female, other), age, and intervention/control group. Migrant students were identified according to their self-identification as "born abroad" on the item "Where were you born?" since this was the information that indicated movement from one country to another during childhood, consistent with our operational definition of a "migrant" (IOM, 2019). The impact of Covid-19 was operationalised by using a context variable whereby $\mathrm{T} 2$ assessment was dichotomised as taking place before or after Covid-19 school closures had commenced. All T1 responses were collected before Covid-19 school closures.

\subsection{Analysis}

First, a series of tests were performed as part of a measurement invariance test for the PSSM and CRIES- 8 scales, to test if they measured the same underlying construct on both timepoints. A model where all parameters were free was compared to a model where the factor loadings of the items were restricted to be equal for the two timepoints. This way each item's influence on the scale remains the same over time. If this test is non-significant, then weak (metric) measurement invariance has been established. In the second test, the model with restricted factor loadings was compared to a model with restricted factor loadings and equal intercepts for the items. If this test is non-significant, then there is strong (scalar) measurement invariance, which is needed to be able to compare the means of the latent variables over time.

After the measurement invariance tests, the model fit and internal consistency of all scales were examined. For the model fit, different fit indices were used, i.e., the chi-square test statistic, Root Means Square Error of Approximation (RMSEA), Standardized Root Mean Square Residual (SRMR), Tucker-Lewis Index (TLI), and Comparative Fit Index (CFI). For the RMSEA, a value below 0.06 was considered a good fit (Hu \& Bentler, 1999) and a value below 0.08 was an acceptable fit (Schreiber et al., 2006). For the SRMR, Hu and Bentler's (1999) recommendation of a value below 0.08 was followed. For CFI and TLI, values above 0.95 were considered a good fit and values above 0.90 were an acceptable fit to the data (Brown, 2015; Hu \& Bentler, 1999). When the fit indices were not acceptable, the models were adjusted based on the standardized factor loadings and modification indices, but only if the suggested changes were theoretically acceptable. Possible changes were the removal of indicators that had weak factor loadings on the underlying scale or adding correlations between error terms. Adjustments were implemented incrementally until an acceptable model was found.

The PSSM scale showed scalar measurement invariance $\left(X_{5}^{2}=1.66, p=0.89\right)$ and an acceptable fit after adding correlations between items 2 ("It is hard for people like me to be accepted here") and 3 ("Sometimes I feel as if I don't belong here"), as well as 1 ("I feel like a real part of my school") and 9 ("I feel proud of belonging to my school"; $X_{134}^{2}=307.72, p=0.07, T L I=0.90$, $C F I=0.91, R M S E A=0.05, S R M R=0.05)$. The scale showed only moderate internal consistency at both timepoints ( $\alpha=0.67$ and $\alpha=0.69$ ). The CRIES- 8 scale also showed strong measurement invariance $\left(X_{8}^{2}=4.37\right.$, $p=0.82)$, and a good model fit $\left(X_{109}^{2}=546.67, p<0.05\right.$, $T L I=0.90, C F I=0.90, R M S E A=0.07, S R M R=0.05)$. Even though the $p$ value was significant, it has been noted that the $p$ value of the chi-squared test is sensitive to sample size (Byrne, 2012; Hu \& Bentler, 1995). Therefore, it is likely that this significance is related to the relatively large sample size. The scale showed good internal consistency at both timepoints $(\alpha=0.86$ and 
$\alpha=0.88)$. The family subscale on the MSPSS scale had a good model fit $\left(X_{2}^{2}=1.35, p=0.05, T L I=1.00, C F I=1.00\right.$, $R M S E A=0.00, S R M R=0.01)$, and high internal consistency $(\alpha=0.92)$. The friends subscale was improved by adding correlations between item 5 ("My friends really try to help me") and 6 ("I can count on my friends when things go wrong"), and this way we reached a good model fit $\left(X_{1}^{2}=1.69, p>0.05, T L I=1,00, C F I=1,00\right.$, $R M S E A=0.03, S R M R=0.01)$. The scale also had high internal consistency $(\alpha=0.92)$. The daily stressors scale showed a good fit $(T L I=0.99, C F I=0.99, R M S E A=0.08$, $S R M R=0.06)$, and high internal consistently $(\alpha=0.92)$. See the average scores on these scales in Table 2.

Next, we performed linear regression, first testing the null model of changes in school belonging over time (between T1 and T2 sum scores in the school belonging scale). Then we added the Covid-19 variable to analyse the effect of Covid-19 school closures on the change in school belonging. In the third step, we ran the full model where change in school belonging was the outcome variable, independent variables were the change in post-traumatic stress symptoms between T1-T2 and social support at $\mathrm{T} 1$, and control variables were age, gender, daily stressors, and intervention group at T1. Linearity, normality, and homoscedasticity were checked and were acceptable. The model explained a very small (1\%) part of the variance in school belonging.

Given the fact that the distribution of data on the T2 Covid-19 variable was unbalanced among the different countries, we also performed a sensitivity analysis. This meant conducting the same linear regression analysis but only on the samples from Denmark, Finland, and the UK that had a variance in the T2 Covid-19 variable. Statistical analyses were carried out using R 4.0.3.

\section{Results}

\subsection{Change in School Belonging and the Effect of Covid-19 School Closures}

In the null model that tested changes between T1 and T2 without any effects, there was a small and non-significant decrease between the two timepoints $(M=-0.68, p=0.12)$. No significant differences on the school level were found (var $=1.28, p=0.72$ ), rendering multilevel analysis unnecessary. Next, we added the Covid-19 assessment variable in the regression model to determine the effect of Covid-19 school closures in the change in school belonging. Students who completed T2 assessment before Covid-19 school closures presented with a decrease of $M=-0.132$ in the sense of school belonging. For students who completed $T 2$ during Covid-19 school closures, this decrease was slightly larger $(M=-0.744)$. However, the difference between the two groups was not significant ( $p=0.200, t=-1.28$ ). These results show that in this sample, Covid-19 cannot be established as impacting changes in school belonging for migrant students.

\subsection{The Effect of Trauma, Social Support, and Other Socio-Demographic Characteristics}

In the next regression model, we inserted all context variables, namely, levels of social support from family and friends, daily stressors, gender and age at T1 to see their effects on the change in school belonging. We also controlled for whether students belonged to an intervention or control group in the larger project to control for any potential effects of the project's interventions on the change in school belonging. In this study, none of these context variables influenced the change in school belonging, except for age (see the overview of results in Table 3). Age was a minorly significant negative predictor in the change in school belonging: older students had slightly decreased levels of school belonging $(M=-0.540$, $S D=0.280, p=0.054$ ).

\subsection{Sensitivity Analysis on a Subsample from Denmark, Finland, and the UK}

Since three countries (Denmark, Finland, and the UK) had a variance in the T2 Covid-19 assessment variable, we conducted a sensitivity analysis on this part of the sample. The same linear regression analysis

Table 2. Average scores on the scales per T2 assessment Covid-19 group ( $N=751$ ).

\begin{tabular}{|c|c|c|}
\hline Scales & $\begin{array}{l}\text { T2 assessment took place before } \\
\text { Covid-19 school closures }(N=366)\end{array}$ & $\begin{array}{l}\text { T2 assessment took place after Covid-19 } \\
\text { school closures started }(\mathrm{N}=385)\end{array}$ \\
\hline PSSM & T1: 42.02 (SD 9.72) & T1: 43.09 (SD 9.73) \\
\hline (school belonging) & T2: 40.31 (SD 10.99) & T2: 42.75 (SD 10.37) \\
\hline CRIES-8 & T1: 10.51 (SD 9.47) & $\mathrm{T} 1: 13.61$ (SD 10.70) \\
\hline (post-traumatic stress symptoms) & T2: 10.72 (SD 9.44) & T2: 13.90 (SD 10.76) \\
\hline $\begin{array}{l}\text { MSPSS friends } \\
\text { (social support from friends) }\end{array}$ & $12.44(S D 4.03)$ & $11.81(S D 3.38)$ \\
\hline $\begin{array}{l}\text { MSPSS family } \\
\text { (social support from family) }\end{array}$ & $12.97(S D$ 3.88) & $13.70(S D 2.69)$ \\
\hline Daily stressors & $21.71(S D 3.91)$ & 20.81 (SD 3.99) \\
\hline
\end{tabular}


Table 3. The effect of Covid-19, post-traumatic stress symptoms, social support, and socio-demographic characteristics in the change in school belonging.

\begin{tabular}{|c|c|c|c|c|}
\hline Predictor & Mean & Standard error & $t$-value & $p$ \\
\hline Covid-19 school closure & 2.487 & 4.063 & 0.612 & 0.541 \\
\hline Intervention & 0.915 & 0.887 & 1.032 & 0.303 \\
\hline Age & -0.540 & 0.280 & -1.927 & 0.054 \\
\hline Gender (male) & -0.144 & 0.881 & -0.163 & 0.870 \\
\hline Gender (other) & 9.716 & 6.559 & 1.481 & 0.142 \\
\hline Daily stressors & -0.076 & 0.109 & -0.700 & 0.484 \\
\hline Friends support & 0.105 & 0.183 & 0.572 & 0.568 \\
\hline Family support & -0.098 & 0.231 & -0.425 & 0.671 \\
\hline Change in trauma & -0.061 & 0.057 & -1.062 & 0.288 \\
\hline Friend support * Covid-19 school closures & -0.391 & 0.265 & -1.473 & 0.142 \\
\hline Family support * Covid-19 school closures & 0.072 & 0.306 & 0.236 & 0.813 \\
\hline Change in trauma $*$ Covid-19 & 0.032 & 0.086 & 0.374 & 0.710 \\
\hline
\end{tabular}

was performed, following the same analytical steps as described in the analysis of the whole dataset (see the overview of results in Table 4). Just as before, school belonging decreased between $\mathrm{T} 1$ and $\mathrm{T} 2$, but this change was not significant $(M=-1.288, p=0.135)$, and Covid-19 had no effect on that change (Covid-19 mean effect on difference in school belonging $M=-1.927, p=0.299$; before Covid-19 group $M=0.157, p=0.910)$. Compared to the analysis on the whole dataset, we detected that here age did not significantly influence the change in school belonging ( $M=-0.246, S D=0.509, p=0.629$ ). On the other hand, the change in post-traumatic stress symptoms had a slightly negative and significant influence on the change in school belonging $(M=-0.429$, $S D=0.193, p=0.027)$. In other words, if post-traumatic stress symptoms increased, school belonging decreased. However, we also found a significant interaction effect between the change in post-traumatic stress symptoms and the type of Covid-19 group $(M=0.472, S D=0.213$, $p=0.029)$. These results indicate that the change in post-traumatic stress symptoms had almost no influence on those who were assessed before Covid-19 school closures $(M=0.043)$. Therefore, the finding that increasing post-traumatic stress symptoms predict decreasing school belonging is applicable for those who were assessed at $\mathrm{T} 2$ after school closures started.

\section{Discussion}

This study investigated the impact of Covid-19 school closures on changes in migrant students' sense of school belonging in secondary schools in six European countries. School belonging was understood as part of educational inclusion (Kovač \& Vaala, 2021; Shaw et al., 2021), and in

Table 4. Sensitivity analysis: The effect of Covid-19, post-traumatic stress symptoms, social support, and socio-demographic characteristics in the change in school belonging.

\begin{tabular}{lcrrr}
\hline Predictor & Mean & Standard error & $t$-value & $p$ \\
\hline Covid-19 school closure & 4.526 & 9.071 & 0.499 & 0.619 \\
Intervention & 1.211 & 1.457 & 0.831 & 0.407 \\
Age & -0.246 & 0.509 & -0.483 & 0.629 \\
Gender (male) & 2.048 & 1.479 & 1.384 & 0.167 \\
Gender (other) & 11.819 & 7.174 & 1.647 & 0.100 \\
Daily stressors & -0.088 & 0.197 & -0.448 & 0.654 \\
Friends support & -0.393 & 0.437 & -0.899 & 0.377 \\
Family support & 0.494 & 0.598 & 0.826 & 0.409 \\
Change in trauma & -0.429 & 0.193 & -2.221 & 0.027 \\
Friend support * Covid-19 school closures & 0.195 & 0.493 & 0.396 & 0.695 \\
Family support * Covid-19 school closures & -0.659 & 0.685 & -0.962 & 0.336 \\
Change in trauma * Covid-19 & 0.472 & 0.213 & 2.219 & 0.029 \\
\hline
\end{tabular}


the context of the particular difficulties that migrant students face in negotiating school belonging (Kia-Keating \& Ellis, 2007; Souto-Manning, 2021; Van Caudenberg et al., 2020). We approached school belonging as a multilayered concept (Allen \& Kern, 2017; Allen et al., 2018; Halse, 2018; Puroila et al., 2021), and investigated the impact of some demographic (i.e., gender, age), individual (i.e., post-traumatic stress symptoms), social (i.e., perceived social support from friends and family), and environmental (Covid-19 school closures) factors in the changing feeling of school belonging (Allen \& Kern, 2017).

In this study, the sense of school belonging decreased over time, but this change was not statistically significant. Despite previous concerns about the negative influence of Covid-19 on mental health, curricular learning and school participation (EC JRC, 2020; Nearchou et al., 2020; OECD, 2021), this study observed no impact of Covid-19 school closures on the decrease in school belonging. This result might imply that physical distancing alone may not have affected decreased feelings of school belonging and that further research is necessary to uncover the complex relationship between Covid-19 school closures and sense of belonging. Building on previous literature, despite the challenges migrant students potentially encountered in their school environments during Covid-19, they might have been able to develop feelings of belonging otherwise (Halse, 2018), for example, through connecting in online spaces (Rowan et al., 2021). This finding may also be related to the fact that interrupted schooling was not necessarily a new experience for many migrant students (Chang-Bacon, 2021), and that migrant students with interrupted schooling are still able to maintain school engagement (Potochnick, 2018). While further research is necessary in this regard, it might be that some migrant students are more familiar with abruptly changing school arrangements and thus may develop and sustain school belonging in ways that might not necessarily require a continuous physical presence on school sites. Another explanation could be that schools in this sample have made sufficient efforts during Covid-19 to maintain connections with migrant students and to sustain feelings of belonging. Our field observations confirm that some teachers made remarkable efforts to care for and connect with migrant students, and these actions might have made a difference in this sample. However, these observations were not registered quantitatively, and more systematic quantitative research is, therefore, necessary to conclude on this matter.

Previous research has often emphasised the role of school belonging as a protective factor in wellbeing (Kia-Keating \& Ellis, 2007; Nuttman-Shwartz, 2019; Scharpf et al., 2020). Some have asserted that mental health problems also influence feelings of belonging to school (Allen \& Kern, 2017; Allen et al., 2018). This study did not confirm a relationship between the change in post-traumatic stress symptoms and the change in school belonging using our whole sample. However, interestingly, the sensitivity analysis showed a small negative influence of increasing post-traumatic stress symptoms on school belonging. At the same time, increasing post-traumatic stress symptoms had almost no effect on those who completed T2 assessment before Covid-19 school closures. This result means that it may be the effect of increasing post-traumatic stress symptoms and Covid-19 school closures together that negatively influenced school belonging. However, this tendency was detected in a small subset of data in three countries, and not as an overall trend in the whole dataset. Therefore, we do not aim to generalise these findings to other populations and note that larger-scale investigations are necessary to make any conclusions on this matter. Future research could also focus on the differences between student groups who score within the clinical range of post-traumatic stress disorder, and those who do not.

Furthermore, we were also interested in the effect of perceived social support from family and friends in the change in school belonging. This was important since previous research indicated that peer support had a positive impact on school belonging (Allen et al., 2018; Ambrose, 2020; Ho et al., 2017), as well as family support at home (Allen et al., 2018; $\mathrm{Hu} \& \mathrm{Wu}, 2020$ ). Investigating the effects of social support structures was also pertinent as previous research indicates that migrant students experienced challenges to participation in online teaching during Covid-19 school closures (OECD, 2021; Primdahl et al., 2021). This study did not detect any effect of perceived social support in the change in school belonging. These findings might be explained by the fact that belonging specifically in school contexts is not only related to social relationships, but also to other learning-related identifications such as curricular learning, learning motivation, emotions, and efficacy (Allen et al., 2018; Fong Lam et al., 2015; Pendergast et al., 2018). Academic belonging is an important part of school belonging for migrant students, as they often have high aspirations and ambitions for learning and educational achievement (Devine, 2009; Lynnebakke \& Pastoor, 2020; Van Caudenberg et al., 2020). For migrant students, there can be also other points of belonging to a school, such as a place that provides routines and care, stability, and safety, or that represents a new way of life and educational opportunities (De Jacolyn et al., 2021; Lynnebakke \& Pastoor, 2020). Further research is necessary to closely understand the specific types of social support that impact migrant students' sense of school belonging.

Several methodological limitations to this study must be considered. First, it is possible that we did not detect any effect due to low statistical power related to low sample size. Second, T2 assessments were conducted at different points during home confinement. Feelings of belonging might have been different after a few days, a week, or many weeks away from school, and further research could investigate what impact the time spent in home confinement might have had on the changing feeling of school belonging. Thirdly, the management of the 
Covid-19 school closures and efforts to maintain school participation and feelings of belonging for migrant students might have been very different across the various countries. While statistically, we did not find school-level differences in the sense of school belonging, the type of schooling practices during Covid-19 school closures might have had an important role, which is currently not captured statistically by this study. Consequently, further studies are needed to uncover how migrant students experienced the changing schooling arrangements, such as distance learning, online environment, and less physical contact with their friends and teachers, and how that impacted their sense of school belonging. Qualitative studies could reveal how migrant students gave meaning to their experiences of belonging during Covid-19 school closures.

While the findings of this study are limited due to the constraints listed above, they still provide important contributions to the currently emerging scholarship on Covid-19 school closures, belonging, and inclusion. They pose crucial questions for future investigations and may inspire researchers and practitioners to further explore the nuanced ways in which migrant students feel belonging to school during Covid-19. While the findings of this study are relevant starting points for future research, we do not claim that they can be generalised, due to the limitations mentioned above. What we do point out with these findings is that belonging is a complex experience, and does not function in the same way for all students, and for migrant students in particular (Allen et al., 2018; Halse, 2018; Souto-Manning, 2021; Van Caudenberg et al., 2020; Yuval-Davis, 2004). Therefore, migration-, Covid-19-, and school practicerelated components have to be considered in order to provide a nuanced picture. Listening to migrant students themselves about the specific barriers they encountered, the practices that worked well for them during school closures, and how they wish schools to foster belonging is crucial for inclusion during the currently ongoing Covid-19 pandemic. We suggest researchers and practitioners think about belonging with an open mindset, considering the many ways in which migrant students can understand and develop belonging (Gao et al., 2019; Halse, 2018) during Covid-19.

\section{Acknowledgments}

This article is an outcome of the RefugeesWellSchool project, which has received funding from the European Union's Horizon 2020 research and innovation programme under grant agreement no. 754849. We would like to thank the adolescents, parents, and school staff members who participated in this project. We are also grateful to the whole RefugeesWellSchool consortium.

\section{Conflict of Interests}

The authors declare no conflict of interests.

\section{References}

Abu El-Haj, T. R., \& Skilton, E. (2017). Toward an awareness of the "colonial present" in education: Focusing on interdependence and inequity in the context of global migration. Curriculum Inquiry, 47(1), 69-79.

Adams-Wiggins, K. R. (2020). Whose meanings belong? Marginality and the role of microexclusions in middle school inquiry science. Learning, Culture and Social Interaction, 24. https://doi.org/10.1016/j.Icsi. 2019.100353

Ainscow, M., Booth, T., \& Dyson, A. (2006). Improving schools, developing inclusion. Routledge.

Allen, K.-A., \& Kern, M. L. (2017). School belonging in adolescents. Theory, research and practice. Springer.

Allen, K.-A., Kern, M. L., Vella-Brodrick, D., Hattie, J., \& Waters, L. (2018). What schools need to know about fostering school belonging: A meta-analysis. Educational Psychology Review, 30(1), 1-34.

Ambrose, A. (2020). To belong or not? In S. Lund (Ed.), Immigrant incorporation, education, and the boundaries of belonging (pp. 41-63). Palgrave Macmillan.

Booth, T., \& Ainscow, M. (2002). Index for inclusion: Developing learning and participation in schools. Centre for Studies on Inclusive Education.

Bronfenbrenner, U. (1994). Ecological models of human development. In T. Husen \& T. N. Postlethwaite (Eds.), International encyclopedia of education (2nd ed., Vol. 3, pp. 1643-1647). Elsevier.

Brown, T. A. (2015). Confirmatory factor analysis for applied research. Guilford Press.

Byrne, B. M. (2012). Structural equation modeling with Mplus: Basic concepts, spplications, and programming. Routledge.

Chang-Bacon, C. K. (2021). Generation interrupted: Rethinking "students with interrupted formal education"(SIFE) in the wake of a pandemic. Educational Researcher, 50(3), 187-196.

Chou, K. L. (2000). Assessing Chinese adolescents' social support: The multidimensional scale of perceived social support. Personality and Individual Differences, 28(2), 299-307.

Cowden, R. G., Govender, K., Oppong Asante, K., Reardon, C., \& George, G. (2018). Validation of the perceived sense of school membership scale: A South African version. Journal of Psychoeducational Assessment, 36(4), 411-417.

D’hondt, F., Van Houtte, M., \& Stevens, P. A. (2015). How does ethnic and non-ethnic victimization by peers and by teachers relate to the school belongingness of ethnic minority students in Flanders, Belgium? An explorative study. Social Psychology of Education, 18(4), 685-701.

De Jacolyn, E., Stasiak, K., \& McCool, J. (2021). "Just be strong, you will get through it": A qualitative study of young migrants' experiences of settling in New Zealand. International Journal of Environmental Research and Public Health, 18(3). https://doi.org/ 
10.3390/ijerph18031292

Delgado, M. Y., Ettekal, A. V., Simpkins, S. D., \& Schaefer, D. R. (2016). How do my friends matter? Examining Latino adolescents' friendships, school belonging, and academic achievement. Journal of Youth and Adolescence, 45(6), 1110-1125.

DeNicolo, C. P., Yu, M., Crowley, C. B., \& Gabel, S. L. (2017). Reimagining critical care and problematizing sense of school belonging as a response to inequality for immigrants and children of immigrants. Review of Research in Education, 41(1), 500-530.

Devine, D. (2009). Mobilising capitals? Migrant children's negotiation of their everyday lives in school. British Journal of Sociology of Education, 30(5), 521-535.

Dimopoulos, K., Koutsampelas, C., \& Tsatsaroni, A. (2021). Home schooling through online teaching in the era of Covid-19: Exploring the role of homerelated factors that deepen educational inequalities across European societies. European Educational Research Journal, 20(4). https://doi.org/10.1177\% 2F14749041211023331

Edgeworth, K., \& Santoro, N. (2015). A pedagogy of belonging: Troubling encounters with ethnic and religious difference. Cambridge Journal of Education, 45(4), 415-426.

Emery, L., Spruyt, B., \& Van Avermaet, P. (2021). Teaching to the track: Grouping in reception education for newly arrived migrant students. International Journal of Inclusive Education. Advance online publication. https://doi.org/10.1080/13603116.2021.1942568

European Commission Joint Research Centre. (2020). Educational inequalities in Europe and physical school closures during Covid-19. https://ec.europa. eu/jrc/sites/jrcsh/files/fairness_pb2020_wave04_ covid_education_jrci1_19jun2020.pdf

Fong Lam, U., Chen, W. W., Zhang, J., \& Liang, T. (2015). It feels good to learn where I belong: School belonging, academic emotions, and academic achievement in adolescents. School Psychology International, 36(4), 393-409.

Gaete, J., Montero-Marin, J., Rojas-Barahona, C. A., Olivares, E., \& Araya, R. (2016). Validation of the Spanish version of the psychological sense of school membership (PSSM) scale in Chilean adolescents and its association with school-related outcomes and substance use. Frontiers in Psychology, 7. https://doi. org/10.3389/fpsyg.2016.01901

Gao, F., Lai, C., \& Halse, C. (2019). Belonging beyond the deficit label: the experiences of "non-Chinese speaking" minority students in Hong Kong. Journal of Multilingual and Multicultural Development, 40(3), 186-197.

Gogolin, I. (2021). Multilingualism: A threat to public education or a resource in public education? European histories and realities. European Educational Research Journal, 20(3), 297-310.

Goodenow, C. (1993). The psychological sense of school membership among adolescents: Scale develop- ment and educational correlates. Psychology in the Schools, 30(1), 79-90.

Halse, C. (2018). Theories and theorising of belonging. In C. Halse (Ed.), Interrogating belonging for young people in schools (pp. 1-29). Palgrave Macmillan.

Ho, N. K. N., Schweitzer, R. D., \& Khawaja, N. G. (2017). Academic achievement among recently arrived Chinese adolescent migrants: The role of social support, school belonging, and acculturative stress. Journal of Psychologists and Counsellors in Schools, 27(1), 24-36.

Hu, B., \& Wu, W. (2020). Parental support in education and social integration of migrant children in urban public schools in China. Cities, 106. http://doi.org/ 10.1016/j.cities.2020.102870

Hu, L., \& Bentler, P. M. (1995). Evaluating model fit. In R. Hoyle (Ed.), Structural equation modeling: Issues, concepts, and applications (pp. 76-99). SAGE.

Hu, L. T., \& Bentler, P. M. (1999). Cutoff criteria for fit indexes in covariance structure analysis: Conventional criteria versus new alternatives. Structural Equation Modeling: A Multidisciplinary Journal, 6, $1-55$.

International Organization for Migration. (2019). International migration law No. 34: Glossary on migration. https://publications.iom.int/books/internationalmigration-law-ndeg34-glossary-migration

Kia-Keating, M., \& Ellis, H. (2007). Belonging and connection to school in resettlement: Young refugees, school belonging and psychosocial adjustment. Clinical Child Psychology \& Psychiatry, 12, 29-43.

Kovač, V. B., \& Vaala, B. L. (2021). Educational inclusion and belonging: A conceptual analysis and implications for practice. International Journal of Inclusive Education, 25(10), 1205-1219.

Lynnebakke, B., \& Pastoor, L. D. W. (2020). "It's very hard, but I'll manage." Educational aspirations and educational resilience among recently resettled young refugees in Norwegian upper secondary schools. International Journal of Qualitative Studies on Health and Well-being, 15. https://doi.org/ 10.1080/17482631.2020.1785694

Magalhães, S. D. S., Miranda, D. K., Paula, J. J. D., Miranda, D. M. D., Romano-Silva, M. A., \& Malloy-Diniz, L. F. (2018). Psychometric properties of a Brazilian Portuguese version of the Children's revised impact of event scale (CRIES-8). Archives of Clinical Psychiatry, 45, 27-32.

Moberg Stephenson, M., \& Källström, Å. (2020). Making sense of places: Belonging among "unaccompanied" young migrants in kinship care in a Swedish suburb. Child \& Family Social Work, 25(4), 742-750.

Nearchou, F., Flinn, C., Niland, R., Subramaniam, S. S., \& Hennessy, E. (2020). Exploring the impact of Covid-19 on mental health outcomes in children and adolescents: A systematic review. International Journal of Environmental Research and Public Health, 17(22). https://doi.org/10.3390/ijerph17228479 
Niehaus, K., Rudasill, K. M., \& Rakes, C. R. (2012). A longitudinal study of school connectedness and academic outcomes across sixth grade. Journal of School Psychology, 50(4), 443-460.

Nuttman-Shwartz, O. (2019). The moderating role of resilience resources and sense of belonging to the school among children and adolescents in continuous traumatic stress situations. The Journal of Early Adolescence, 39(9), 1261-1285.

OECD. (2021). The state of school education: One year into the Covid pandemic.

Pastoor, L. D. W. (2015). The mediational role of schools in supporting psychosocial transitions among unaccompanied young refugees upon resettlement in Norway. International Journal of Educational Development, 41, 245-254.

Pendergast, D., Allen, J., McGregor, G., \& Ronksley-Pavia, M. (2018). Engaging marginalized, "at-risk" middlelevel students: A focus on the importance of a sense of belonging at school. Education Sciences, 8(3). https://doi.org/10.3390/educsci8030138

Perrin, S., Meiser-Stedman, R., \& Smith, P. (2005). The children's revised impact of event scale (CRIES): Validity as a screening instrument for PTSD. Behavioural and Cognitive Psychotherapy, 33(4), 487-498.

Pincton, F., \& Banfield, G. (2019). Using Bourdieu to understand the pathways to belonging that are forged by young students of refugee experience in an Australian mainstream school. In S. Habib \& M. R. M. Ward (Eds.), Identities, youth and belonging (pp. 105-122). Palgrave MacMillan.

Potochnick, S. (2018). The academic adaptation of immigrant students with interrupted schooling. American Educational Research Journal, 55(4), 859-892.

Primdahl, N. L., Borsch, A. S., Verelst, A., Jervelund, S. S., Derluyn, I., \& Skovdal, M. (2021). "It's difficult to help when I am not sitting next to them": How Covid-19 school closures interrupted teachers' care for newly arrived migrant and refugee learners in Denmark. Vulnerable Children and Youth Studies, 16(1), 75-85.

Puroila, A. M., Juutinen, J., Viljamaa, E., Sirkko, R., Kyrönlampi, T., \& Takala, M. (2021). Young children's belonging in Finnish educational settings: An intersectional analysis. International Journal of Early Childhood, 53(1), 9-29.

Ramirez, S., Aldunate, M. P., Arriagada, C., Bueno, M., Cuevas, F., González, X., Araya, R., \& Gaete, J. (2021). Brief research report: The association between educational experiences and Covid-19 pandemic-related variables, and mental health among children and adolescents. Frontiers in Psychiatry, 12. https://doi.org/ 10.3389/fpsyt.2021.647456

Rowan, L., Beavis, C., Tran, L., Blackmore, J., McCandless, T., Hoang, T., Hurem, A., \& Halse, C. (2021). International students in the first years of senior secondary schooling in Australia: Longing for belonging. International Journal of Educational Development, 81. http://dx.doi.org/10.1016/j.ijedudev.2020.102347
Rutland, A., Cameron, L., Jugert, P., Nigbur, D., Brown, R., Watters, C., Hossain, R., Landau, A., \& Le Touze, D. (2012). Group identity and peer relations: A longitudinal study of group identity, perceived peer acceptance, and friendships amongst ethnic minority English children. British Journal of Developmental Psychology, 30(2), 283-302.

Scharpf, F., Kaltenbach, E., Nickerson, A., \& Hecker, T. (2020). A systematic review of socio-ecological factors contributing to risk and protection of the mental health of refugee children and adolescents. Clinical Psychology Review, 83. https://doi.org/10.1016/ j.cpr.2020.101930

Schreiber, J. B., Nora, A., Stage, F. K., Barlow, E. A., \& King, J. (2006). Reporting structural equation modeling and confirmatory factor analysis: A review. Journal of Educational Research, 99, 323-338.

Schwartz, K. D., Exner-Cortens, D., McMorris, C. A., Makarenko, E., Arnold, P., Van Bavel, M., Williams, S., \& Canfield, R. (2021). Covid-19 and student wellbeing: Stress and mental health during return-toschool. Canadian Journal of School Psychology, 36(2), 166-185.

Schweitzer, R. D., Mackay, S., Hancox, D., \& Khawaja, N. G. (2021). Fostering belonging in a CALD school environment: Learning from a research collaboration with a refugee and migrant school community in Australia. Intercultural Education, 32(6). https://doi.org/ 10.1080/14675986.2021.1985803

Shaw, P. A., Messiou, K., \& Voutsina, C. (2021). Illuminating young children's perceived notions of inclusion in pedagogical activities. International Journal of Inclusive Education, 25(4), 499-516.

Souto-Manning, M. (2021). On the abolition of belonging as property: Toward justice for immigrant children of color. Urban Education. Advance online publication. https://doi.org/10.1177\%2F00420859211017967

Spaas, C., Verelst, A., Devlieger, I., Aalto, S., Andersen, A. J., Durbeej, N., Hilden, P. K., Kankaanpää, R., Langer Primdahl, N., Opaas, M., Osman, F., Peltonen, K., Sarkadi, A., Skovdal, M., Smith Jervelund, S., Soye, E., Watters, C., Derluyn, I., Colpin, H., \& De Haene, L. (2021). Mental health of refugee and non-refugee migrant young people in European secondary education: the role of family separation, daily material stress and perceived discrimination in resettlement. Journal of Youth and Adolescence. Advance online publication. https://doi.org/10.1007/s10964021-01515-y

Szelei, N., Pinho, A. S., \& Tinoca, L. (2021). “Foreigners in our schools": Cultural diversity, Othering and the desire for justice in schools. Urban Education. Advance online publication. https://doi.org/ 10.1177\%2F00420859211058420

Szelei, N., Tinoca, L., \& Pinho, A. S. (2020). Professional development for cultural diversity: The challenges of teacher learning in context. Professional Development in Education, 46(5), 780-796. 
UNESCO. (2005). Guidelines for inclusion: Ensuring access to education for all.

Van Caudenberg, R., Clycq, N., \& Timmerman, C. (2020). Feeling at home in school: Migrant youths' narratives on school belonging in Flemish secondary education. European Educational Research Journal, 19(5), 428-444.

Vervliet, M., Derluyn, I., \& Broekaert, E. (2010). Daily stressors scale for young refugees. Unpublished manuscript.

Vervliet, M., Lammertyn, J., Broekaert, E., \& Derluyn, I.
(2014). Longitudinal follow-up of the mental health of unaccompanied refugee minors. European Child \& Adolescent Psychiatry, 23, 337-346.

Yuval-Davis, N. (2004). Borders, boundaries and the politics of belonging. In S. May, T. Modood, \& J. Squires (Eds.), Ethnicity, nationalism and minority rights (pp. 214-230). Cambridge University Press.

Zimet, G. D., Dahlem, N. W., Zimet, S. G., \& Farley, G. K. (1988). The multidimensional scale of perceived social support. Journal of Personality Assessment, 52(1), 30-41.

\section{About the Authors}

Nikolett Szelei is a postdoctoral researcher at the Centre for the Social Study of Migration and Refugees, Ghent University, Belgium. She holds a PhD in education, specialising in teacher education. Her interests are multilingualism, multiculturalism, and social justice in education and migration. Previously she worked as an early childhood educator and primary school teacher.

Ines Devlieger is a postdoctoral researcher at Ghent University in Belgium, Faculty of Psychology and Educational Sciences. Her major research interests include data analysis.

An Verelst is a psychosocial manager at the Centre of Expertise for Psychosocial Support for Victims of Collective Emergencies of the Belgian government, and a postdoctoral researcher at Ghent University, Belgium. She holds an MA in clinical psychology, an MA in cultures and development, and a PhD from Ghent University in educational sciences. Her research interests are the psychosocial impact of migration, terrorism, armed conflict, and sexual violence and its implications for treatment.

Caroline Spaas is a clinical child psychologist, family therapist, and doctoral researcher at KU Leuven, Faculty of Psychology and Educational Sciences. Her research focuses on child development in refugee children and adolescents, and on relational processes of post-trauma reconstruction in community-based care for refugee children, adolescents, and their families.

Signe Smith Jervelund has an educational background in public health sciences and is an associate professor in health services research. Her research has a particular focus on vulnerable groups and social and ethnic inequality in access to healthcare (in both a national and international comparative perspective), and how we can overcome these inequalities in health and promote integration using a complex intervention research framework.

Nina Langer Primdahl works as a research assistant at the University of Copenhagen, where she has also earned an MA in public health. Her research interests are health equity, minority health, and participatory methodologies.

Morten Skovdal is a community health and applied social psychologist, earning his PhD from the London School of Economics and Political Science. His research focuses on the contextual factors and relational processes that shape engagement with health services and promote psychosocial wellbeing and care in the community. He is particularly interested in involving underserved groups in research, both to challenge dominant narratives and to attune interventions to their lived realities.

Marianne Opaas is a researcher at the Norwegian Centre for Violence and Traumatic Stress Studies in Oslo, Norway, and has her PhD from the Psychological Department, University of Oslo. Her research interests are traumatic stress, refugees' mental health, wellbeing and exile life functioning, and the longitudinal trajectories of trauma-affected adult refugees before, during, and after therapy. She is also a clinical psychologist and has worked clinically with refugees and other client groups for more than 30 years.

Natalie Durbeej is a behavioural scientist and an associate professor in public health at the Department of public health and caring sciences, Uppsala University. Her research interests include mental health problems in children and youth, as well as the evaluation of preventive interventions to reduce mental health problems in these populations. 
Fatumo Osman is a registered nurse, senior lecturer, and associate professor at Dalarna University. She is also a researcher at CHAP, Uppsala University. Her research focuses on developing and evaluating culturally tailored parenting support programs for migrant parents living in Sweden. Current research projects involve sustainability of parenting programs as well as school interventions to promote the mental health of refugee and migrant children.

Emma Soye is a doctoral researcher at the University of Sussex. Emma has an MA in development studies and has conducted research on refugee education and wellbeing for organisations including the Institute of Development Studies, Save the Children UK, and UNICEF. She currently lectures on MA and BA modules on migrant and refugee wellbeing at the University of Sussex.

Hilde Colpin is a full professor at the Faculty of Psychology and Educational Sciences at KU Leuven. Her research focuses on the role of proximal social relationships in families and schools for children and adolescents' social-emotional and academic development, and on the interplay between teacher-student and peer relationships at school. These topics are studied with a variety of research designs, e.g., longitudinal designs and randomized controlled trials.

Lucia De Haene is an associate professor at the Faculty of Psychology and Educational Sciences, KU Leuven, where she conducts research on refugee family relationships and clinical intervention for refugee families and communities. As a family therapist, she coordinates her team in transcultural trauma care for refugees at the Faculty Clinical Centre and leads the development of the child psychiatry daycare unit Paso of the University Psychiatry Hospital (UPC KU Leuven).

Sanni Aalto is a clinical psychologist and doctoral candidate at Tampere University, Finland. Her major research interests include psychosocial interventions promoting migrant wellbeing and integration. Previously she has worked as a clinical psychologist in child psychiatry.

Reeta Kankaanpää is a doctoral researcher at Tampere University, Finland. Her major research interests include the evaluation of psychometric properties of survey instruments, intervention effectiveness research, and migrant wellbeing.

Kirsi Peltonen is a senior researcher working at the Research Centre for Child Psychiatry. She has studied the mental health of children with various adverse experiences, and her main focus is on trauma interventions among war-affected children.

Arnfinn J. Andersen was research director of the Norwegian Centre for Violence and Traumatic Studies (NKVTS) from 2010 to 2018 , where he is now head of the section for trauma, catastrophes, and forced migration-adults and elderly. He has a doctoral degree (dr. polit.) in sociology. His research has focused on masculinity, gender, family structures, forced migration, violent extremism, social networks, and friendships.

Per Kristian Hilden (PhD) is a social/medical anthropologist, affiliated as a senior researcher with the Norwegian Centre for Violence and Traumatic Stress Studies. Hilden's research interests include culture of medical systems, migration and global health, inequality in health, social justice, marginalisation, and stigma.

Charles Watters is professor of well-being and social care at the School of Education and Social Work, University of Sussex. His major research interests include migration, health, and social care, with a particular focus on the well-being of refugee children.

Ilse Derluyn is full professor at Ghent University, Department of Social Work and Social Pedagogy (Belgium). Her main research topics concern the wellbeing of (unaccompanied) migrant and refugee children, war-affected children, and victims of trafficking. Ilse is actively involved in supporting refugees and practitioners working with these groups and in policy research. She published many international publications, is the PI of the ERC-SG ChildMove and coordinator of the H2020 RefugeesWellSchool project. Ilse heads the Centre for the Social Study of Migration and Refugees (CESSMIR) and is co-director of the Centre for Children in Vulnerable Situations (CCVS). 